\title{
DFT Study of a Novel Organic Film: The Structural versus Magnetic Effects
}

\author{
S. Simonetti, ${ }^{1,2}$ A. Juan, ${ }^{1}$ G. Brizuela, ${ }^{1}$ and S. Ulacco ${ }^{2}$ \\ ${ }^{1}$ Universidad Nacional del Sur (UNS), Consejo Nacional de Investigaciones Científicas y Técnicas (CONICET), \\ Avenida Alem 1253, 8000 Bahía Blanca, Argentina \\ ${ }^{2}$ Universidad Tecnológica Nacional (UTN), 11 de Abril 461, 8000 Bahía Blanca, Argentina
}

Correspondence should be addressed to S. Simonetti; ssimonet@uns.edu.ar

Received 23 September 2015; Revised 5 November 2015; Accepted 15 November 2015

Academic Editor: Miquel Solà

Copyright (C) 2015 S. Simonetti et al. This is an open access article distributed under the Creative Commons Attribution License, which permits unrestricted use, distribution, and reproduction in any medium, provided the original work is properly cited.

\begin{abstract}
Unsaturated fatty acids have great interest by their activities as industrial materials in novel applications. In the present work, the cis-3-hexenoic acid (HA) adsorbed on the $\mathrm{Ni}(111)$ surface was studied by first-principles calculations using the Vienna Ab Initio Simulation Package (VASP). The most stable location for HA is presented on top site of Ni(111), although the energies are very similar for all the adsorption sites. The surface-molecule interaction takes place between the carboxyl group of HA and surrounding $\mathrm{Ni}$ atoms. The adsorption is weak and consequently the metal-molecule length is enhanced. The carboxyl group is elongated and weakened after adsorption giving rise to a shift in stretching frequencies. There are notable changes on the magnetic moments values of Ni surface atoms neighboring to the molecule that mainly induced magnetic moments on $\mathrm{O}$ and $\mathrm{H}$ atoms. Noticeable charge transfer occurs in $3 \mathrm{~d} 4 \mathrm{~s}, \mathrm{p}$ Ni orbitals and $2 \mathrm{~s} \mathrm{C}, 2 \mathrm{~s} \mathrm{p} \mathrm{O}, 1 \mathrm{~s} \mathrm{H}$ orbitals of carboxyl group. The surface presents positive work function changes after adsorption as a consequence of an electron back-donation. During interaction, the significance of the magnetic effects over the structural effects is evidenced. This sets the stage for a future adsorption process improvement based on the modification of the surface magnetic properties.
\end{abstract}

\section{Introduction}

The development of thin organic films on various substrates has attracted strong interest due to the use of organic films in novel electronic applications, such as optoelectronic devices, sensors, and field effect transistors [1]. Acids usually form close-packed monolayer films with chains highly oriented on substrates. Previous studies have reported the adsorption of stearic acid on gold [2], aluminum [3], and copper and silver [4]. However, there are no detailed reports of organic acids on magnetic metals.

Unsaturated fatty acids have attracted big interest by their behavior as medical and industrial materials. The knowledge of dipole moment of molecules to nanotechnology is related within the functionality of these compounds producing designed products for specific applications [5]. The design of materials in nanoscale can be rearranged through interactions such as electrostatic dipole, van der Waals interactions, and hydrophobic and hydrophilic interactions. An example of this arrangement is the induced self-aggregation where the arrangement of the molecules is driven under control through an external magnetic field or electrical field [6]. On the other hand, unsaturated fatty acids are widely distributed in biological tissues as a main constituent of biomembranes. These acids promote fluidity and control the phase transition behavior depending on the environmental condition [7]. In addition, in technology for new materials, hydrophobic nanoparticles of copper capped with oleic acid were prepared to prevent oxidation [8]. In spite of such importance, only a little is known about the molecular-order structures and the physicochemical properties of unsaturated acids on magnetic metals. The development of modern theoretical surface science provides an opportunity to investigate surfaces and adsorbate structures on the atomic scale with useful applications in industrial technologies. A detailed study of the interaction of organic films adsorbed on the metal substrates is usually focused in the surface geometry and the electronic properties. In addition, when the substrate is magnetic, many 
other effects can also be studied such as magnetic proximity effect between the molecule and the magnetic substrates [9]. Focusing on magnetic substrates, there is a vast chemical industry based on the catalytic properties of nickel. Nickel is one of the most versatile heterogeneous metal catalysis. Its chemical stability makes it a very convenient election in a lot of applications. The adsorption of molecular hydrogen on an ultrathin layer of $\mathrm{Ni}(111)$ hydride has been researched by Shan et al. [10]. Carrasco and colleagues have theoretically studied the adsorption of $\mathrm{CO}$ and $\mathrm{C}$ on $\mathrm{Ni}(111)$ surface [11]. The characterization of stearic acid adsorption on $\mathrm{Ni}(111)$ surface by experimental and first-principles study approach has been investigated by Liang et al. [12]. Focusing on the adsorbed organic acid, specifically, the cis-3-hexenoic acid $\left(\mathrm{C}_{5} \mathrm{H}_{9} \mathrm{COOH}\right)$ is an unsaturated acid that presents a double bond in the center of the chain and, due to their regular and simple organic structure, the obtained results can be used in the prediction of the adsorption and catalytic behavior to other industrial acids of longer chain (e.g., oleic acid) [13] with a significant reduction in computational requirements (e.g., system size and computational time).

In this work, the cis-3-hexenoic acid (HA) adsorbed on $\mathrm{Ni}(111)$ surface is studied by first-principles calculation. The physical-chemical, magnetic, and structural effects taking place during adsorption are analyzed. The theory and model is described in the next section.

\section{Theory and Model}

The calculations were performed in the framework of the Density Functional Theory (DFT) using the Vienna Ab Initio Simulation Package [14] applying Grimme's D2 correction [15]. The electron projector augmented wave method was used and the generalized gradient approximation with the Perdew-Burke-Ernzerhof functional was employed. Cut-off energy of $400 \mathrm{eV}$ was employed for the fixed convergence of the plane-wave expansion. This value is in agreement with that reported in $[16,17]$ and it is based on a previous test where the calculation error was lower than $0.01 \mathrm{eV}$. A set of $3 \times 3 \times$ 1 Monkhorst-Pack $k$-points was used to sample the Brillouin Zone while the ground state was obtained using a MethfesselPaxton smearing of $0.2 \mathrm{eV}$. The computations were performed at the spin-polarized level in order to evaluate the magnetic properties of the systems. The Ni(111) surface of FCC stacking layered structure was represented with a periodically repeated slab containing five layers of atoms separated in the normal direction by a vacuum region. The width of this gap was optimized to avoid the interaction between slabs. The lattice constants for Ni bulk were optimized obtaining a value of $3.53 \AA$ that is in agreement with the experimental value [18]. A box of $20 \times 20 \times 20 \AA^{3}$ was used to obtain the isolated molecule energy.

The molecule was placed on one side of the slab and its geometry was permitted to relax completely together with the uppermost three uppermost layers of the metallic slab. The adsorption energy $\left(E_{\text {ads }}\right)$ was calculated as the difference between the energy of the HA molecule adsorbed on $\mathrm{Ni}$
TABLE 1: Adsorption energies and surface-molecule distances for cis3-hexenoic on the adsorption sites of $\mathrm{Ni}(111)$.

\begin{tabular}{lccc}
\hline & Energy $(\mathrm{eV})$ & $\mathrm{O}_{\mathrm{I}}-\mathrm{Ni}_{\mathrm{I}}$ distance $(\AA)$ & $\mathrm{H}-\mathrm{Ni}_{\mathrm{I}}$ distance $(\AA)$ \\
\hline Top & -2.65 & 2.676 & 2.013 \\
Hollow & -2.47 & 2.600 & 1.714 \\
Bridge & -2.50 & 2.745 & 1.747 \\
\hline
\end{tabular}

surface $\left(E_{\text {HA-Nisurf }}\right)$ and the sum of the free Ni surface $\left(E_{\text {Nisurf }}\right)$ and the isolated HA molecule $\left(E_{\mathrm{HA}}\right)$ energies:

$$
E_{\mathrm{ads}}=\left(E_{\mathrm{HA}-\mathrm{Nisurf}}\right)-\left[\left(E_{\mathrm{Nisurf}}\right)+\left(E_{\mathrm{HA}}\right)\right]
$$

The adsorption energies were calculated in order to compare the stability of the molecule adsorbed on the different surface sites. A negative value indicates an exothermic adsorption process.

In the present work, the binding preference site and the adsorption energies of HA molecule on the $\mathrm{Ni}(111)$ surface model are investigated. Some electronic characteristics as the density of orbital states (DOS), the changes in the work function, and the magnetic moment are evaluated. The vibrational properties are also calculated. The influence of spin polarization on adsorption with the hope of future applicability in the optimization of adsorption and catalytic behavior is analyzed.

\section{Results and Discussion}

3.1. Adsorption Energy and Site Preference. An accurate calculation of the adsorption energy for a given system is the starting point to understanding of the mechanism of catalytic activity. The adsorption energy describes the strength of the chemical bond between adsorbate and substrate. Different adsorption sites for cis-3-hexenoic acid (HA) on $\mathrm{Ni}(111)$ surface were considered; specifically, they are top, hollow, and bridge sites (see Figure 1). In Table 1, the equilibrium interatomic distances and the adsorption energies for HA adsorbed on the different sites of the $\mathrm{Ni}(111)$ surface are summarized. The internal geometry of the molecule does not change significantly in presence of the substrate, independently of the adsorption site. The energies are similar for all the sites; the more stable location for $\mathrm{HA}$ is presented on top $\mathrm{Ni}(111)$ site. Figure 2 shows lateral and top views of HA molecule adsorbed on top $\mathrm{Ni}(111)$ site. The cis-3hexenoic acid is adsorbed on $\mathrm{Ni}(111)$ surface via carboxyl group. The acid group $(\mathrm{COOH})$ of the molecule interacts with surrounding $\mathrm{Ni}$ atoms while the long chain extends away from the surface. The molecule-surface distances depend slightly on the adsorption site (see Table 1). In general, the height of the molecule on the surface is established by the expansion of the metal d orbitals. For the higher coordinated sites, the height of the molecule on the surface is also influenced by the nearest neighbor distance of the substrate atoms. The distance between the molecule and the nearest metal atoms decreases if the extension of the interacting metal orbitals decreases. At the same time, the molecule will adsorb at higher heights if the metal has a small lattice 


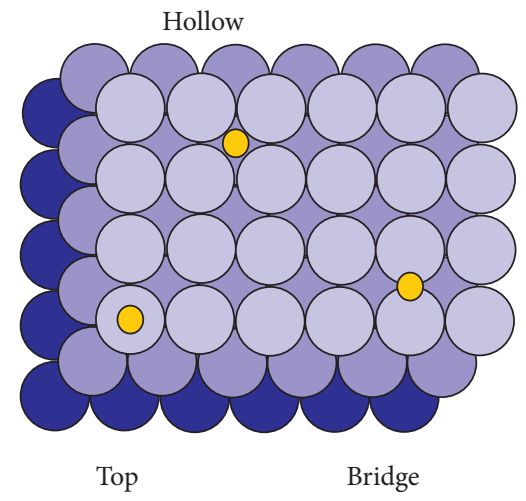

(a)

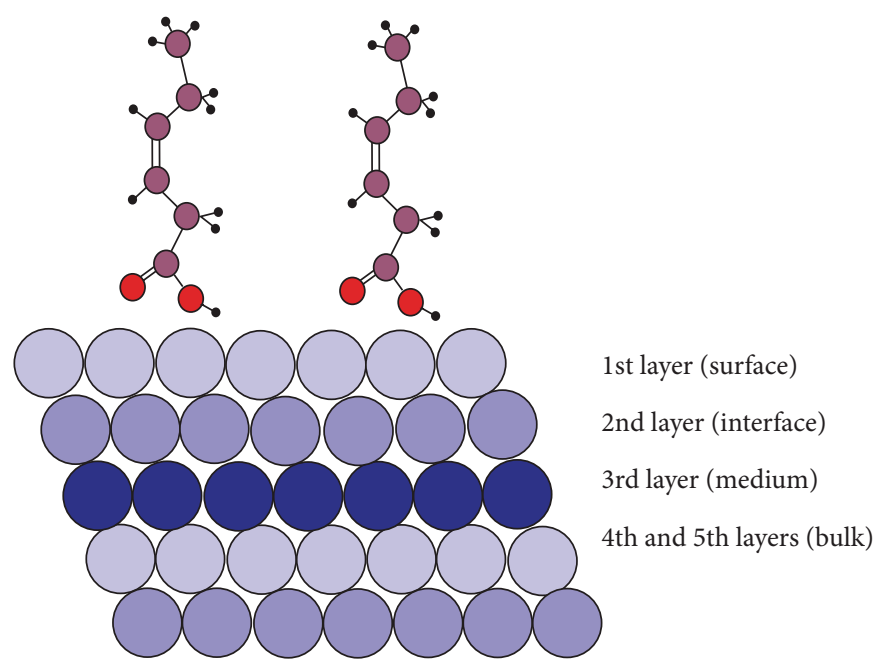

(b)

Figure 1: Schematic (a) top and (b) side views of the fcc Ni(111) surface. The investigated high-symmetry sites are indicated with yellow circles.

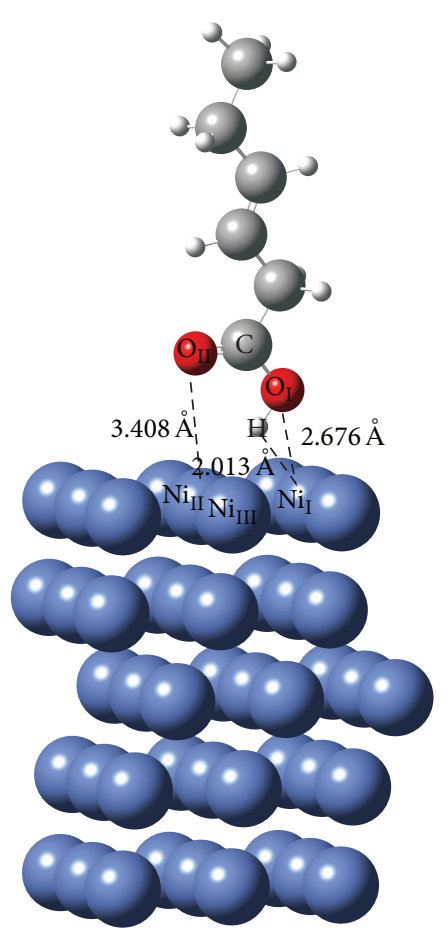

(a)

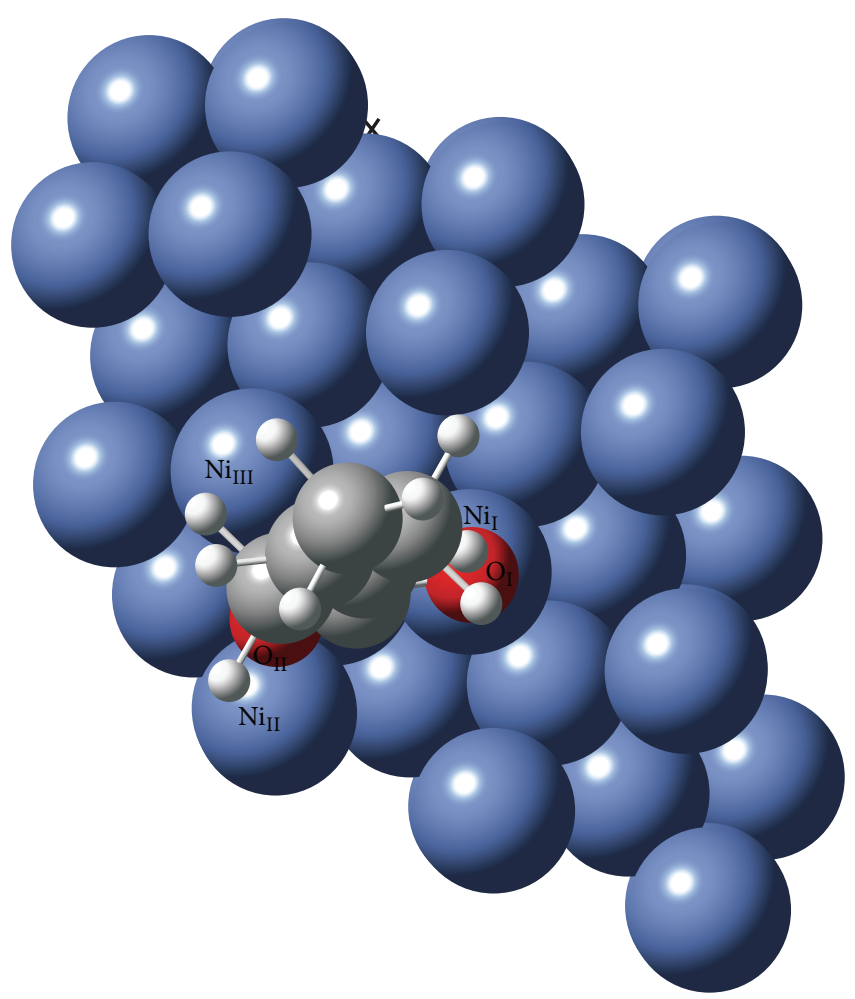

(b)

FIgURE 2: (a) Lateral and (b) top views of cis-3-hexenoic acid adsorbed on top Ni(111) site.

constant. In our studio, the HA molecule adsorbs at the distances shown in Table 1 as compromise between the small lattice constant of nickel (compared with other transition metals) and the influence of Ni d orbitals. The local density of states (LDOS) graphics of the s, p, and d band obtained from a spin-polarized calculation indicates that Ni surface exhibits dispersion of $\mathrm{s}$ and $\mathrm{p}$ bands much larger than $\mathrm{d}$ band, indicating the much more contracted nature of $\mathrm{Ni} \mathrm{d}$ orbitals.
The computed electronic configuration for the surface atoms of bare $\mathrm{Ni}(111)$ is $\mathrm{d}^{8.3} \mathrm{~s}^{0.5} \mathrm{p}^{0.4}$. The electron occupation of the valence $s$ orbitals seems to be slightly lower and that of the $\mathrm{p}$ orbitals slightly greater. Similar characteristics have been reported by Wong and Hoffmann [19], where the role of $\mathrm{s}, \mathrm{p} \mathrm{Ni}$ orbitals and the contracted nature of $\mathrm{d}$ orbitals were also emphasized in the discussion. The authors indicated that there is little doubt that the $\mathrm{d}$ orbitals are involved in 
adsorbate-surface bonding, but the combined effect of the $s$ and $p$ bands is much more important [19]. The changes in the DOS of these orbitals after adsorption are thus much less obvious than those of the $\mathrm{d}$ bands; the $\mathrm{s}$ and $\mathrm{p}$ bands of a transition metal are very diffuse and their band widths are tens of $\mathrm{eV}$. The authors remark that besides the $\mathrm{d}$ bands, the $s$ and $\mathrm{p}$ bands also play a significant role in the bonding [19]. As a result, the authors expose that the role of the $s$ and $\mathrm{p}$ orbitals on chemisorption involving transition metals is seldom discussed, and they claim that these orbitals should interact with the adsorbate [19]. The contribution of Ni s, p and d orbitals has also been reported by Germán et al. for the cyclopentene (c-C5H8) dehydrogenation to cyclopentadienyl anion (c-C5H5 ${ }^{-}$) on $\mathrm{Ni}(111)$ [20], while Liang et al. have reported that $\mathrm{Ni} 4 \mathrm{~s}$ orbital plays an important role in the adsorption of the stearic acid on $\mathrm{Ni}(111)$ [12]. Gupta remarks the importance of $\mathrm{p}$ orbital during $\mathrm{H}$ hydride formation in $\mathrm{Ni}$ metals [21]. A wavefunction analysis indicates the large delocalization of the states of s-p character, the narrow $\mathrm{d}$ band weak interacting atomic like states, and the importance of $\mathrm{Ni}$ p orbital in the bonding [21].

At this stage, it is useful to compare the adsorption geometry of noble metals. The noble metals present differences from other metals; this reveals the completely filled $\mathrm{d}$ band and consequently a different bonding mechanism. Adsorption on the noble metals is notably weaker and hence the metal-molecule lengths are increased. Even though nickel is not a noble metal, its behavior corresponds in some way because it presents a quasi-filled $\mathrm{d}$ band. According to calculations, $E_{\text {ads }}$ is weak, decreases for on-top site, and increases for sites with higher coordination (see Table 1).

Adsorption may also correlate with the electronegativity of the adatoms, that is, with how strongly an atom will attract electrons from the surrounding atoms. In relationship, $\mathrm{Ni}$ atoms have more affinity to interact with $\mathrm{H}$ atom than $\mathrm{O}$ atoms of carboxyl group and, therefore, the $\mathrm{H}$-surface distance is presented as the shortest. The electronegativity differences and, in consequence, the electron exchange contribute to the adsorption behavior (the charge density redistribution is analyzed in Section 3).

In next sections, in absence of a preferential adsorption site, the HA molecule located on top site of $\mathrm{Ni}(111)$ was selected to study the electronic, magnetic characteristics and the vibrational properties of the system.

3.2. Magnetic Moment. The dipole moment change was analyzed considering different contributions. As postulated above, the surface-molecule interaction takes place between the $\mathrm{COOH}$ group of the acid of the molecule and the surrounding Ni atoms. The local magnetic moments for the different atoms of our slab model were calculated. The atom number indicates the position of the atom in the $\mathrm{Ni}(111)$ slab: 1 (surface), 2 (interface), 3 (medium), and 4 (bulk) (see Figure 1). Table 2 shows the magnetic moment of $\mathrm{Ni}$ atoms and the $\mathrm{OH}$ atoms of carboxyl group. The results show that magnetic moments were mainly induced on the $\mathrm{O}$ and $\mathrm{H}$ atoms by proximity to the $\mathrm{Ni}$ atoms. The magnetic moment is enhanced for HA atoms neighboring to the Ni surface where the proximity effect is stronger. Small magnetic moment for
TABLE 2: Magnetic moment ( $\mu \mathrm{B} /$ atom) for each Ni no equivalent atom in the slab and the $\mathrm{OH}$ atoms ( $\mathrm{COOH}$ group) involves in the cis-3-hexenoic acid-surface interaction.

\begin{tabular}{lcc}
\hline Atom & \multicolumn{2}{c}{ Magnetic moment $(\mu \mathrm{B} /$ atom $)$} \\
& Isolated Ni & Ni-HA \\
\hline $\mathrm{Ni} 1$ & 0.643 & 0.701 \\
\hline $\mathrm{Ni} 2$ & 0.639 & 0.654 \\
\hline $\mathrm{Ni} 3$ & 0.610 & 0.602 \\
\hline $\mathrm{Ni} 4$ & 0.652 & 0.636 \\
\hline $\mathrm{O}$ & $0.61^{*}$ & -0.003 \\
\hline $\mathrm{H}$ & - & -0.002 \\
\hline
\end{tabular}

Ni 1: atom of the surface.

$\mathrm{Ni}$ 2: atom of the interface.

$\mathrm{Ni}$ 3: atom of the medium.

Ni 4: atom of the bulk.

${ }^{*}$ Experimental [18].

$\mathrm{O}$ and $\mathrm{H}$ atoms of $\mathrm{HA}$ molecule is obtained. Conversely, the magnetic moments of interacting $\mathrm{Ni}(1)$ atoms increase at least by $8.27 \%$ with respect to the clean surface. Greater changes of the magnetic moments values of $\mathrm{Ni}$ atoms were obtained; it seems that the physical cause of this electron enrichment is inherent to the chemisorption bonding with the HA molecule.

In general, the magnetic moment for surface $\mathrm{Ni}(1)$ and interface $\mathrm{Ni}(2)$ atoms increases while the magnetic moment for medium $\mathrm{Ni}(3)$ and bulk $\mathrm{Ni}(4)$ atoms decreases after adsorption (see Table 2). On the other hand, the magnetic moment for surface $\mathrm{Ni}(1)$ atom of pure $\mathrm{Ni}$ differs from that of $\mathrm{Ni}(4)$ atom in the bulk of pure $\mathrm{Ni}: 0.643 \mu \mathrm{B}$ in comparison with $0.654 \mu \mathrm{B}$ for bulk Ni. This is a property that occurs for the presence of surface states and contracted bands. The surface $\mathrm{Ni}(1)$ atom in the $\mathrm{Ni}(111)$ slab has the largest $\mathrm{Ni}$ magnetic moment $(0.701 \mu \mathrm{B})$ after $\mathrm{HA}$ adsorption, which is enhanced by $9.42 \%$ with respect to that of bulk $\mathrm{Ni}(4)$ $(0.636 \mu \mathrm{B})$. It confirms the importance of band hybridization on the Ni magnetization. The magnetic moment of the $\mathrm{C}$ atom (of $\mathrm{COOH}$ group) also changes, in a fewer percent comparing with $\mathrm{O}$ and $\mathrm{H}$ atoms; the reasons are that $\mathrm{C} 2 \mathrm{~s}$, $2 \mathrm{p}$ population was changed by adsorption inducing a charge transfer and hybridization interaction. The HA adsorption on top site has the surface $\mathrm{Ni}$ atoms with lowest magnetic moments value (comparing adsorption on all the $\mathrm{Ni}(111)$ sites); thus, the system presents the better stability.

3.3. Electronic Structure: $d$ Band Centre and Charge Density Redistribution. The electronic structure supplied important information about the interaction between adsorbate and substrate and their effect on the binding energy and the geometrical structure. The position of the $\mathrm{d}$ band center of the isolated surface is another important quality which is associated with the strength of the molecule-surface interaction. As the width of the $d$ band increases, the energy is reduced and the distance of the molecule on the surface should increase. The $\mathrm{d}$ band center takes part in the bonding for many molecule-surface interactions where the major contact 


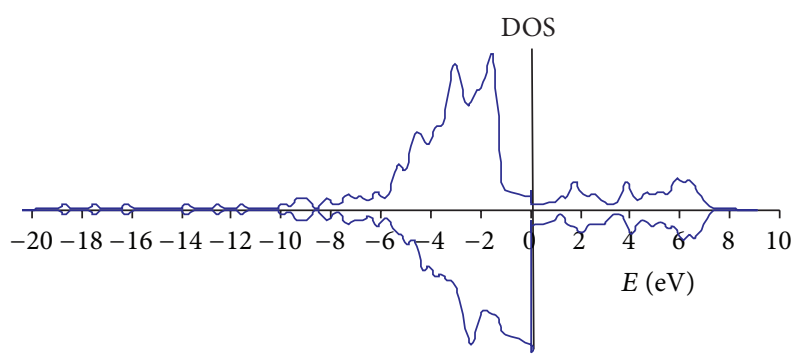

(a)

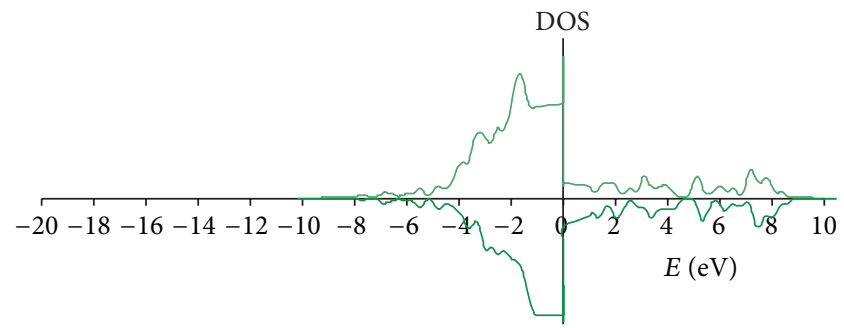

(b)

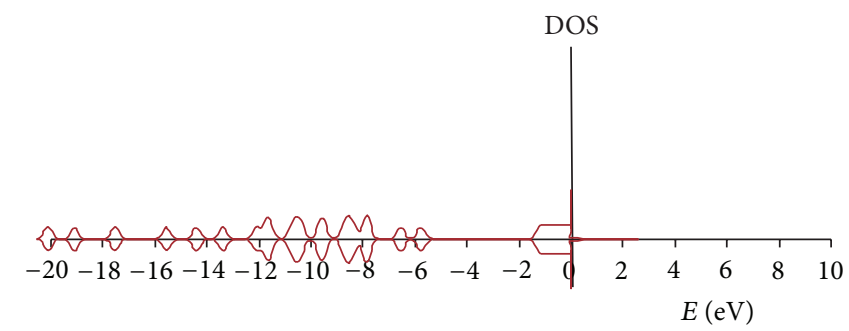

(c)

FIGURE 3: Density of states (DOS) obtained from spin-polarized calculation for the systems: (a) cis-3-hexenoic acid/Ni(111), (b) clean Ni(111), and (c) isolated cis-3-hexenoic acid. The origin of the energy scale corresponds to the Fermi level.

is due to hybridization of the adsorbate frontiers orbitals and the substrate d orbitals.

The density of states (DOS) for the HA adsorbed on top $\mathrm{Ni}(111)$ surface is shown in Figure 3(a). For comparison, the densities of states of both the clean $\mathrm{Ni}(111)$ surface (Figure 3(b)) and the isolated HA molecule (Figure 3(c)) were also calculated. In the spin-polarized calculations, the average between the $\mathrm{Ni}(111) \mathrm{d}$ band centers obtained for up and down cases was taken from the $\mathrm{Ni} d$ band local density of states (LDOS) [22]. The $\mathrm{Ni} d$ band expands from -5 to $-0.5 \mathrm{eV}$ and, therefore, the center is located to about $4.5 \mathrm{eV}$. These values are in agreement with ab initio and semiempirical results reported in [22-26]. The system's total DOS nearby the Fermi energy is dominated by the Ni surface, but, in a deeper energy level, the system DOS is affected by the adsorbed molecule (Figure 3(a)). The location of d-states with respect to the molecule frontiers orbitals is an important factor to predict the facility to the metallic surface to form a chemical bond with the molecule. In this work, the molecule-surface overlapping occurs within -8 and $-0.5 \mathrm{eV}$; Ni d-states and also s, p Ni states are involved in the interaction with HA. As the molecule approaches the surface, the localized HA orbitals are shifted to lower energies. The HA orbitals have a lesser task in the interaction with the surface because they are completely occupied and characterized by Pauli repulsion. In general, after adsorption, the changes on the DOS peaks increase with coordination: the higher the coordination is the greater the DOS peaks change. In our study, there are no significant changes because Figure 3 shows the molecule located on the lower coordination site.

As known, the difference in spin-up and spin-down states is the basis of the Ni magnetism. The spin unbalance decreases considerably upon HA adsorption. The formation of molecule-surface interactions increases the DOS with respect to $\mathrm{Ni}$ pure, showing a coupling between $\mathrm{Ni}$ orbitals and $\mathrm{COOH}$ orbitals, which induces a larger magnetic moment per $\mathrm{Ni}$ atom. Accordingly, there are electronic charge density changes in the substrate and adsorbate orbitals. The formation of the surface-HA bond exhibits electron rearrangement between the bonding species. The HA charge density is redistributed and some of it is transferred into antibonding orbitals, which weakens the $\mathrm{COOH}$ bond. The Ni surface had influence on the adsorbed molecular electronic properties; consequently, we have calculated the charge transfer during adsorption. The results show that the charge transfer mainly happens on the interface between carboxyl and Ni surface (see Table 3). For HA adsorption on top $\mathrm{Ni}(111)$, the charge transfer percentages are as follows: $4 \mathrm{~s} \mathrm{Ni}$ (between -0.61 and $-1.20 \%$ ), $4 \mathrm{p} \mathrm{Ni}$ (between $+1.86 \%$ and $+3.45 \%$ ), and $3 \mathrm{~d} \mathrm{Ni}$ (between $+0.24 \%$ and $0.49 \%$ ) for $\mathrm{Ni}$ nearest neighbors and $2 \mathrm{~s} \mathrm{C}(-0.47 \%), 2 \mathrm{p} \mathrm{C}(-0.12 \%), 2 \mathrm{~s} \mathrm{O}_{\mathrm{I}}$ $(+0.54 \%), 2 \mathrm{p} \mathrm{O}_{\mathrm{I}}(-0.93 \%), 2 \mathrm{~s} \mathrm{O}_{\mathrm{II}}(-0.12 \%), 2 \mathrm{p} \mathrm{O}_{\mathrm{II}}(-0.72 \%)$, and $1 \mathrm{~s} \mathrm{H}(-11.72 \%)$ of carboxyl group. The population of the second nearest $\mathrm{Ni}$ atom modifies a very little amount; this indicates a majority participation of the Ni first neighbor orbitals; the influence is mainly limited to the system interface.

3.4. Work Function. When the molecule is adsorbed on the surface the work function change is immediately associated with the change of the electric dipole in the surface and it can be calculated as the difference between the work function of the metal surface with and without the adsorbed molecule. The electron donation from molecule to surface is presumed to reduce the work function, while the backdonation from surface to molecule increases this property. Accordingly, metallic surface with positive work function change after adsorption presents an electron back-donation that conduces to a positive dipole moment. Evaluating the Ni surface work function upon the HA chemisorption with 
TABLE 3: Electronic orbital density charges for the atoms that participate in the interactions.

\begin{tabular}{lccc}
\hline \multirow{2}{*}{ Atom } & \multicolumn{3}{c}{ Electron charge } \\
& $\mathrm{s}$ & $\mathrm{p}$ & $\mathrm{d}$ \\
\hline \multirow{2}{*}{$\mathrm{Ni}_{\mathrm{I}}$} & 0.485 & 0.384 & $8.345^{\mathrm{a}}$ \\
& 0.488 & 0.376 & $8.304^{\mathrm{b}}$ \\
\hline \multirow{2}{*}{$\mathrm{Ni}_{\text {II }}$} & 0.482 & 0.377 & $8.323^{\mathrm{a}}$ \\
& 0.488 & 0.377 & $8.293^{\mathrm{b}}$ \\
\hline \multirow{2}{*}{$\mathrm{Ni}_{\text {III }}$} & 0.484 & 0.384 & $8.328^{\mathrm{a}}$ \\
& 0.489 & 0.377 & $8.308^{\mathrm{b}}$ \\
$\mathrm{C}$ & 0.854 & $1.695^{\mathrm{a}}$ & - \\
& 0.858 & $1.695^{\mathrm{b}}$ & - \\
\hline \multirow{2}{*}{$\mathrm{O}_{\mathrm{I}}$} & 1.688 & $3.633^{\mathrm{a}}$ & - \\
\hline \multirow{2}{*}{$\mathrm{O}_{\mathrm{II}}$} & 1.679 & $3.667^{\mathrm{b}}$ & - \\
\hline \multirow{2}{*}{$\mathrm{H}$} & 1.695 & $3.604^{\mathrm{a}}$ & - \\
& 1.697 & $3.630^{\mathrm{b}}$ & - \\
\hline
\end{tabular}

${ }^{\mathrm{a}}$ After adsorption.

${ }^{\mathrm{b}}$ Before adsorption.

TABLE 4: Calculated stretching frequencies for cis-3-hexenoic acid, before and after adsorption on top site of $\mathrm{Ni}(111)$.

\begin{tabular}{lcc}
\hline & Free HA & HA/Ni(111) \\
\hline$v_{\mathrm{O}-\mathrm{H}}\left(\mathrm{cm}^{-1}\right)$ & 3027 & 2164 \\
& 2168 & 2077 \\
\hline$\nu_{\mathrm{C}=\mathrm{O}}\left(\mathrm{cm}^{-1}\right)$ & 1655 & 1678 \\
\hline
\end{tabular}

respect to the clean $\mathrm{Ni}$ surface, it is observed that for all the adsorption sites positive work function values are obtained. The increase of the work function is due to the downward dipole direction, induced by the HA molecule. The dipole moment change, produced by the HA on the Ni(111) surface, generates an extraction of the electron from the Ni surface. The work function values present a variation in a range of $0.6-0.9 \mathrm{eV}$. Small variation is evidenced due the absence of a preferential adsorption site.

3.5. Vibrational Frequencies. In general the adsorption energy for the molecule located on a surface stable site corresponds to the absolute minimum while the adsorption energies calculated for other high-symmetry sites correspond to a local minimum energy on the potential energy surface. In this work, we have corroborated that the obtained geometry for $\mathrm{HA}$ on $\mathrm{Ni}(111)$ surface is in true minima and not on the transition state because calculated $\mathrm{HA}$ vibrational frequencies were all real.

Table 4 shows the calculated stretching frequencies of the HA molecule on top $\mathrm{Ni}(111)$. The stretching vibration mode for the HA molecule changes after adsorption. The $\mathrm{HA}$ adsorption on $\mathrm{Ni}(111)$ surface produces a shift to lower frequency values for $\mathrm{OH}$ peak and higher frequency values for $\mathrm{C}=\mathrm{O}$ peak of $\mathrm{COOH}$. These changes in the stretching frequencies are due to the formation of the interaction between
TABLE 5: Calculated bond distances for cis-3-hexenoic acid, before and after adsorption on top site of $\mathrm{Ni}(111)$.

\begin{tabular}{lcc}
\hline Bond & \multicolumn{2}{c}{ Distance $(\AA)$} \\
& Free HA & HA/Ni(111) \\
\hline $\mathrm{C}=\mathrm{O}$ & 1.215 & 1.232 \\
$\mathrm{C}-\mathrm{O}$ & 1.379 & 1.355 \\
$\mathrm{O}-\mathrm{H}$ & 0.974 & 1.041 \\
$-\mathrm{C}-\mathrm{C}$ & 1.513 & 1.508 \\
$\mathrm{C}=\mathrm{C}$ & 1.346 & 1.339 \\
$=\mathrm{C}-\mathrm{C}$ & 1.503 & 1.502 \\
\hline
\end{tabular}

the molecule and the metallic surface. The corresponding molecule geometry shows small changes: elongation of the $\mathrm{C}=\mathrm{O}$ and $\mathrm{O}-\mathrm{H}$ bonds with respect to the isolated molecule while the $\mathrm{C}-\mathrm{C}, \mathrm{C}-\mathrm{O}$, and $\mathrm{C}=\mathrm{C}$ bonds shrink after adsorption (see Table 5). The carboxyl group is elongated and weakened giving rise to a shift in stretching frequencies. Weaker and therefore longer $\mathrm{C}=\mathrm{O}$ and $\mathrm{O}-\mathrm{H}$ bonds imply moleculemetal bonding and result in the shift in $\mathrm{C}=\mathrm{O}$ and $\mathrm{O}-\mathrm{H}$ stretching frequencies. In general, the relationship of bond distance changes on the coordination is smallest for the $3 \mathrm{~d}$ metals. The tendency is presented as follows: the higher surface reactivity, the stronger bonding and population of antibonding orbitals, reflecting more elongated bond lengths and shifting stretching frequencies.

\section{Conclusions}

In the present work, the cis-3-hexenoic acid (HA) adsorbed on $\mathrm{Ni}(111)$ surface was studied by first-principles calculations using the VASP code. The more stable location for HA is presented on top site of $\mathrm{Ni}(111)$, although the energies are very similar for all the adsorption sites. The surfacemolecule interaction takes place between carboxyl group of HA molecule and the surrounding $\mathrm{Ni}$ atoms of surface. Adsorption is weak and the metal-molecule length is enhanced. The carboxyl group is elongated and weakened after adsorption giving rise to a shift in stretching frequencies related to the chemisorption bonding with HA molecule.

There are notable changes of the magnetic moments values of $\mathrm{Ni}$ surface atoms neighboring to the molecule that mainly induced magnetic moments on $\mathrm{O}$ and $\mathrm{H}$ atoms of carboxyl group by proximity. The physical cause of this electron enrichment is inherent to the bonding with the HA molecule. The Ni(111) surface depicts positive work function change after adsorption as a consequence of an electron backdonation. Noticeable charge transfer occurs in $4 \mathrm{~s} \mathrm{p} 3 \mathrm{~d} \mathrm{Ni}$ orbitals and 2s C, 2s p O, 1s H orbitals of carboxyl group.

During interaction, the significance of the magnetic effects over the structural effects is evidenced. This study sets the stage for a future adsorption process improvement based on the modification of the surface magnetic properties.

\section{Conflict of Interests}

The authors declare that there is no conflict of interests regarding the publication of this paper. 


\section{Acknowledgments}

Our work was supported by SCyT UTN, SCyT UNS, and PIPCONICET 0341. A. Juan, G. Brizuela, and S. Simonetti are members of CONICET.

\section{References}

[1] G. Witte and C. Wöll, "Growth of aromatic molecules on solid substrates for applications in organic electronics," Journal of Materials Research, vol. 19, no. 7, pp. 1889-1916, 2004.

[2] J. L. Dote and R. L. Mowery, "Infrared reflectance-absorption spectra of Langmuir-Blodgett stearic acid monolayers on gold and aluminum: influence of substrate," Journal of Physical Chemistry, vol. 92, no. 6, pp. 1571-1575, 1988.

[3] M. S. Lim, K. Feng, X. Chen et al., "Adsorption and desorption of stearic acid self-assembled monolayers on aluminum oxide," Langmuir, vol. 23, no. 5, pp. 2444-2452, 2007.

[4] Y.-T. Tao, "Structural comparison of self-assembled monolayers of n-alkanoic acids on the surfaces of silver, copper, and aluminum," Journal of the American Chemical Society, vol. 115, no. 10 , pp. 4350-4358, 1993.

[5] M. C. Roco, "From vision to the implementation of the U.S. National Nanotechnology Initiative," Journal of Nanoparticle Research, vol. 3, no. 1, pp. 5-11, 2001.

[6] P. L. Gai, R. Roper, and M. G. White, "Recent advances in nanocatalysis research," Current Opinion in Solid State and Materials Science, vol. 6, no. 5, pp. 401-406, 2002.

[7] R. Roy, A. B. Das, and D. Ghosh, "Regulation of membrane lipid bilayer structure during seasonal variation: a study on the brain membranes of Clarias batrachus," Biochimica et Biophysica Acta-Biomembranes, vol. 1323, no. 1, pp. 65-74, 1997.

[8] Y. Jian-Guang, Z. Yuang-Lin, T. Okamoto, R. Ichino, and M. Okido, "A new method for preparing hydrophobic nano-copper powders," Journal of Materials Science, vol. 42, no. 18, pp. 76387642, 2007.

[9] D. P. Liu, Y. B. Hu, H. Guo, and X. F. Han, "Magnetic proximity effect at the molecular scale: first-principles calculations," Physical Review B, vol. 78, no. 19, Article ID 193307, 2008.

[10] J. Shan, A. W. Kleyn, and L. B. F. Juurlink, "Adsorption of molecular hydrogen on an ultrathin layer of $\mathrm{Ni}\left(\begin{array}{lll}1 & 1 & 1\end{array}\right)$ hydride," Chemical Physics Letters, vol. 474, no. 1-3, pp. 107-111, 2009.

[11] J. Carrasco, L. Barrio, P. Liu, J. A. Rodriguez, and M. V. Ganduglia-Pirovano, "Theoretical studies of the adsorption of $\mathrm{CO}$ and $\mathrm{C}$ on $\mathrm{Ni}(111)$ and $\mathrm{Ni} / \mathrm{CeO}_{2}(111)$ : evidence of a strong metal-support interaction," Journal of Physical Chemistry C, vol. 117, no. 16, pp. 8241-8250, 2013.

[12] S. H. Liang, T. Yu, D. P. Liu, W. X. Wang, Y. P. Wang, and X. F. Han, "Characterization of stearic acid adsorption on $\mathrm{Ni}(111)$ surface by experimental and first-principles study approach," Journal of Applied Physics, vol. 109, no. 7, Article ID 07C115, 2011.

[13] F. F. de Sousa, S. G. C. Moreira, S. J. dos Santos da Silva, J. Del Nero, and P. Alcantara Jr., "Dielectric properties of oleic acid in liquid phase," Journal of Bionanoscience, vol. 3, no. 2, pp. 139142, 2009.

[14] http://www.vasp.at/.

[15] S. Grimme, "Semiempirical GGA-type density functional constructed with a long-range dispersion correction," Journal of Computational Chemistry, vol. 27, no. 15, pp. 1787-1799, 2006.

[16] V. Shah, T. Li, H. Cheng, K. Baumert, and D. Sholl, "CO chemisorption on flat and stepped $\mathrm{Ni}$ surfaces: a density functional study Fuel," Chemistry Division Preprints, vol. 47, pp. 217-218, 2002.

[17] M. Gajdoš, A. Eichler, and J. Hafner, "CO adsorption on closepacked transition and noble metal surfaces: trends from ab initio calculations," Journal of Physics Condensed Matter, vol. 16, no. 8, pp. 1141-1164, 2004.

[18] C. Kittel, Introduction to Solid State Physics, John Wiley \& Sons, 1976.

[19] Y.-T. Wong and R. Hoffmann, "A comparative study of the chemisorption of ethene on three metal surfaces: $\mathrm{Ni}(111)$, $\operatorname{Pd}(111)$ and Pt(111)," Journal of the Chemical Society, Faraday Transactions, vol. 86, no. 24, pp. 4083-4094, 1990.

[20] E. Germán, I. López-Corral, A. Juan, and G. Brizuela, "A theoretical study of cyclopentene $\left(\mathrm{c}-\mathrm{C}_{5} \mathrm{H}_{8}\right)$ dehydrogenation

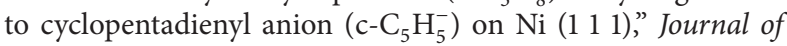
Molecular Catalysis A: Chemical, vol. 314, no. 1-2, pp. 28-34, 2009.

[21] M. Gupta, "Electronic structure of $\mathrm{H}$ in metals," in The Electronic Structure of Complex Systems, P. Phariseau and W. M. Temmerman, Eds., 2012.

[22] M. A. Quiroga, G. F. Cabeza, and N. J. Castellani, "Structural and magnetic properties of Ni/Pt multilayers," Applied Surface Science, vol. 254, no. 1, pp. 355-359, 2007.

[23] E. Germán, S. Simonetti, E. Pronsato, A. Juan, and G. Brizuela, "c- $\mathrm{C}_{5} \mathrm{H}_{5}$ on a $\mathrm{Ni}\left(\begin{array}{lll}1 & 1 & 1\end{array}\right)$ surface: theoretical study of the adsorption, electronic structure and bonding," Applied Surface Science, vol. 254, no. 18, pp. 5831-5836, 2008.

[24] A. W. Edith Chan and R. Hoffmann, " $\mathrm{PF}_{3}, \mathrm{PF}_{2}$, and $\mathrm{PF}$ on $\mathrm{Ni}(111)$ : theoretical aspects of their chemisorption," The Journal of Chemical Physics, vol. 92, no. 1, pp. 699-708, 1990.

[25] A. I. Lichtenstein, M. I. Katsnelson, and G. Kotliar, "Finitetemperature magnetism of transition metals: an ab initio dynamical mean-field theory," Physical Review Letters, vol. 87, no. 6, Article ID 067205, 2001.

[26] S. Simonetti, S. Ulacco, G. Brizuela, and A. Juan, "Computational study of cis-oleic acid adsorption on $\mathrm{Ni}\left(\begin{array}{lll}1 & 1 & 1\end{array}\right)$ surface," Applied Surface Science, vol. 258, no. 15, pp. 5903-5908, 2012. 

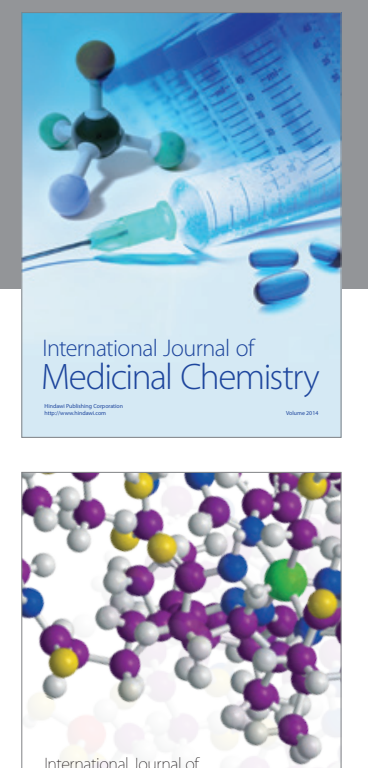

\section{Carbohydrate} Chemistry

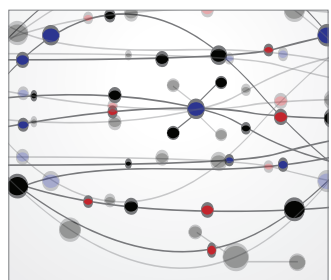

The Scientific World Journal
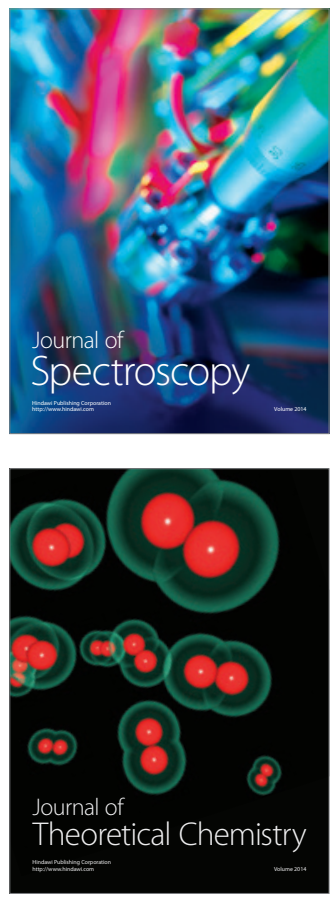
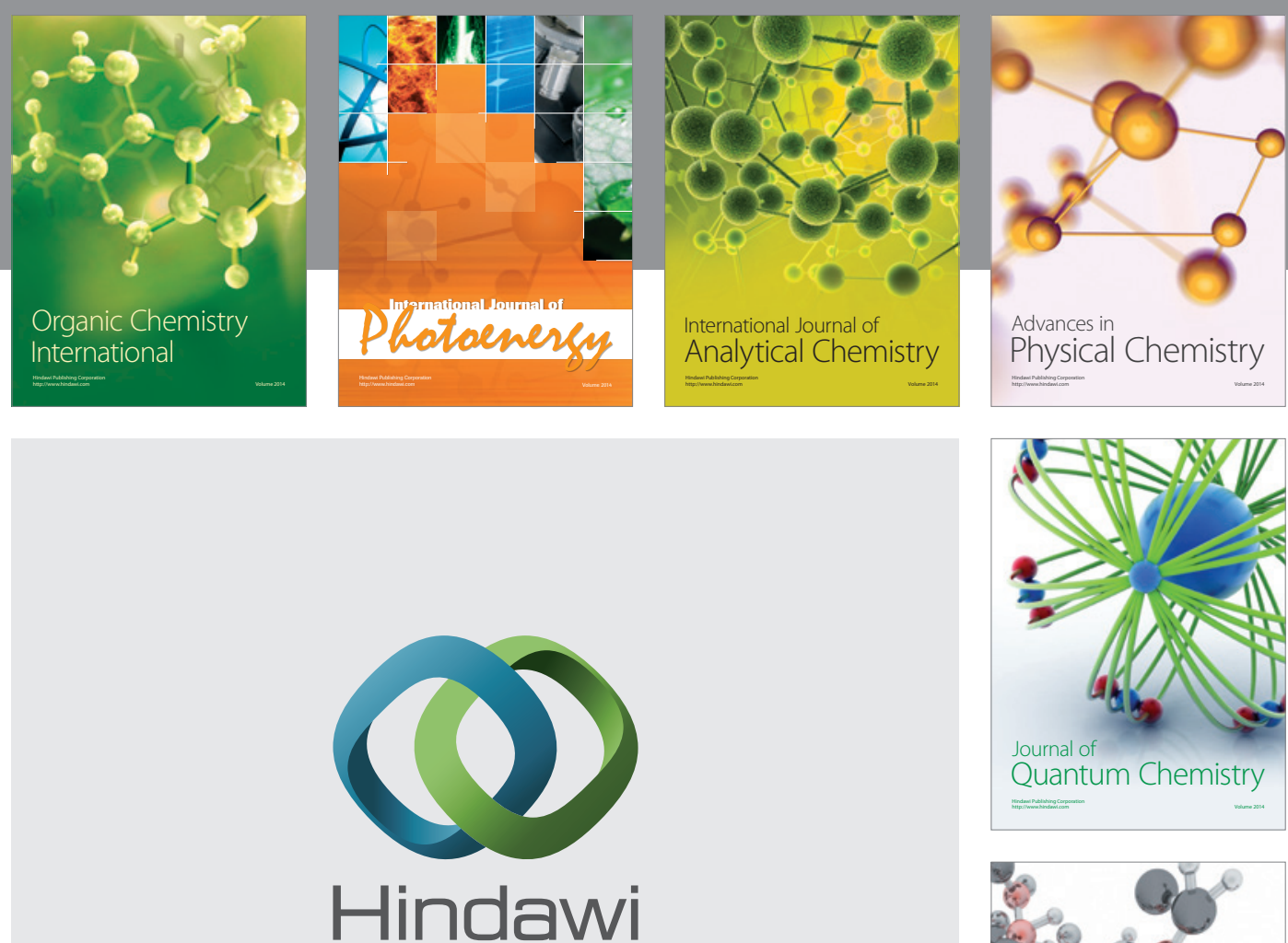

Submit your manuscripts at

http://www.hindawi.com

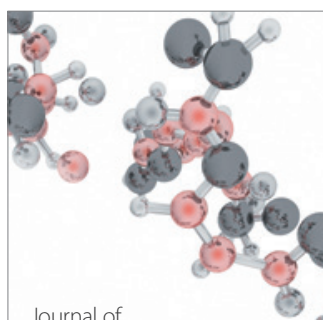

Analytical Methods

in Chemistry

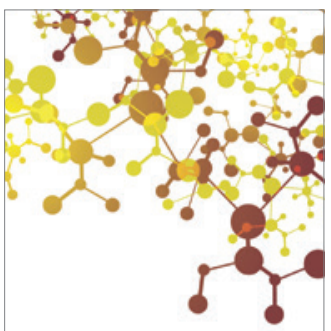

Journal of

Applied Chemistry

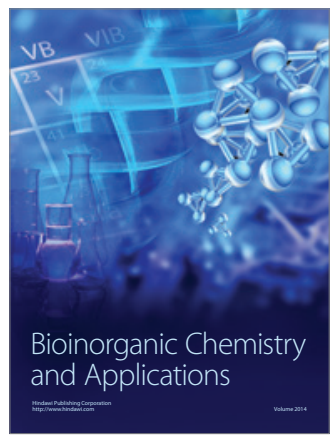

Inorganic Chemistry
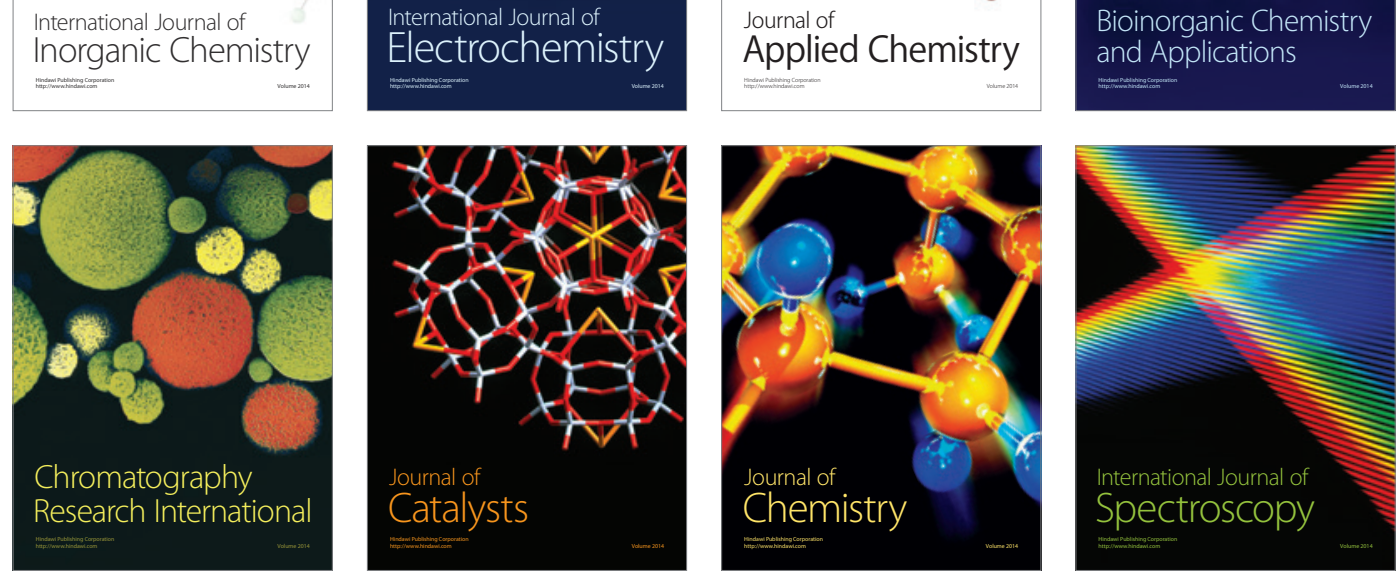